\title{
Correction to: Post-traumatic Splenic Injury Outcomes for Nonoperative and Operative Management: A Systematic Review
}

\author{
Sabrina Gill ${ }^{1} \cdot$ John Hoff $^{1} \cdot$ Ashley Mila $^{1} \cdot$ Carol Sanchez $^{2} \cdot$ Mark McKenney $^{2,3} \cdot$ Adel Elkbuli $^{2}$ (D)
}

Published online: 26 September 2021

(C) Société Internationale de Chirurgie 2021

Correction to: World J Surg (2021) 45:2027-2036

https://doi.org/10.1007/s00268-021-06063-x

Sabrina Gill's, John Hoff's and Ashley Mila's affiliation is correct as reflected here.
Publisher's Note Springer Nature remains neutral with regard to jurisdictional claims in published maps and institutional affiliations.

The original article can be found online at https://doi.org/10.1007/ s00268-021-06063-x.

Adel Elkbuli

adel.elkbuli@hcahealthcare.com

1 Herbert Wertheim College of Medicine, Florida International University, Miami, FL, USA

2 Department of Surgery, Division of Trauma and Surgical Critical Care, Kendall Regional Medical Center, 11750 Bird, Road, Miami, FL 33175, USA

3 Department of Surgery, University of South Florida, Tampa, FL, USA 